\title{
The Structure of Rights in the Context of Private Property
}

\author{
DURAN BELL* \\ University of California
}

\begin{abstract}
Some rights to resources adhere to individuals on the basis of ascribed characteristics-these are rights of person. These rights are not subject to voluntary alienation. And there are rights that adhere to specific characteristics of resources and are subject to alienation. These are rights in property. However, there has been a systematic tendency to promote property rights at the expense of the rights of person and, in so doing, confound the analysis of the commons, of common property, and of private property. Given a delineation of fundamental concepts, this paper examines critically the foundational works of Demsetz and Coase and shows that their theoretical arguments depend on an implicit denial of all rights of person. It is shown, however, that rights of person are not properly analyzable by the standards that apply to rights in property and that the optimal policy to pursue in contemporary society is to determine a desired configuration rights and responsibilities in combination with rights in property.
\end{abstract}

\section{INTRODUCTION}

There can hardly be any word more fraught with meaning than "property." The linguistic history of this term indicates that its current connotation developed rather recently, during the period of an ascendant mercantile and industrial capitalism. Its basic and original meaning had been in reference to a characteristic of a person, so that when first applied to land during the 1700 s, it was understood that property in land was indicative of the social position of the individual who owned it. On this basis, it was quite natural for "property" to be ascribed later to productive capital and industrial plant as those possessions became the more essential indicators of social position.

* Direct all correspondence to: Duran Bell, School of Social Sciences, University of California, Irvine, CA 92717-5100,<Dbell@uci.edu>

Journal of Socio-Economics, Volume 24, No. 4, pp. 607-622

Copyright 01995 JAI Press Inc.

All rights of reproduction in any form reserved.

ISSN: 1053-5357 
According to McPherson (1985), the meaning of property narrowed over time to emphasize exclusive use rights to material things and "then, with the rise of the capitalist market economy, the bulk of actual property shifted from often nontransferable rights to a revenue from land, charters, monopolies, and offices, to transferable rights in freehold land, saleable leases, physical plant, and money. Property became predominantly a right to things" (pp. 81-82). Consequently, property rights came to be associated with the right to effect voluntarily the transfer of resources from one person (or group) to another: the right of alienation.

It is difficult in this day to recognize the revolutionary and culturally peculiar nature of the right of alienation in relation to land ("real property"). As Peters (1994) indicates so powerfully, the customary view of land was as a place to which persons and groups belonged; people were of a place. It was only with the gradual domination of commercial and capitalist interests during the 18th and 19th centuries that full supremacy could be gained for the notion that place was a thing that belonged to the person.

The "people of a place" had been those who by virtue of birth and social station shared with others rights to the use and revenue of some set of resources. Hence, "place" was more than geography; it included quintessentially the corporate group that had use rights to the resources therein. Hence, people and place were, each, both "people and place"; neither being definable without the other.

The concept of the "place of a person" divests the place of its people to become a thing - a thing to be transferred among persons, together with its use rights and revenue rights: it becomes property. Clearly, the people of the place must be ousted as a precondition for this transformation; only then can land devolve from its use as a commons to become an alienable thing of its owner.

During the feudal period, the granting of property rights in land (and serfs) would have been destabilizing since it have would enabled an ambitious noble to begin a process of land aggregation and consolidation that could eventually challenge royal power, itself. However, the Church wanted alienation to be facilitated, at least in the form of bequest, in order to accumulate the wealth of parishioners at the expense of heirs:

The Church discouraged intestacy, protected alienations for its own benefit, enforced written contracts, supported creditors of the dead. To it, more probably than to any other agency, was due the decay of communal society (Jeudwine 1975 [1918], p. 160).

Property rights in estates emerged only slowly during the Middle Ages, experiencing accelerated development with the revolutionary change in laws associated with the Enclosure Acts.

While it is true that there are alienable things in almost every society, those things do not deserve the term "property" unless social position is determined by reference to things. However, in traditional systems, things are not themselves the basis for the determination of social rank; rather, social position tends to be 
the basis for making claims against things. For example, in Imperial China a wealthy peasant could realize prestige from his skill, hard work, and intelligence, but he was still a peasant. Transforming that wealth into social position involved using it for the education of a son and that son's passing of competitive examinations. As for wealthy Chinese merchants, they were largely subject to condemnation no matter how great their wealth in things, unless their resources became the basis for entry into administrative positions.

Property is peculiar to specific social contexts (Peters, 1994; Strathern, 1988). In the more formally structured post-Neolithic societies, social position was not defined directly by goods accumulation. In these societies, things were not property. In order for a thing to become property, it must be possible for social position to be established by processes of goods-accumulation rather than by ascription. Hence, the casual use of that term in ethnographic investigations creates a severe risk of superimposing on other cultures the shadowy fragments of a contemporary Western weltanschauung. Rather than gloss over a wide range of phenomena under the mantle of property and property rights, we should effectively deconstruct property into the essential elements that distinguish specific forms of rights in relation to resources.

\section{CATEGORIES OF RIGHTS}

One may delineate many categories of rights: rights of person, use rights, rights in property, rights in private property, rights in the commons, and rights in common property. The list seems endless; for example, De Allessi (1980) refers to job access rights and job termination rights; and there are the rights to make certain types of "deductions" on income tax forms and countless other rights that are the focus daily of development and amendment in state and federal legislatures. Some of these rights are alienable, some are inalienable, and some have greater consequence for some persons than for others. Out of this mélange of rights, one may be able to discern a "structure of rights" that is defined in terms of the categories of rights and their incidence among categories of person within the social formation. In looking at possible structures of this kind, I will focus special attention on the significance of inalienable rights, to be called rights of person, in the context of a social system dominated by rights in private property.

There are hardly any rights that cannot be abrogated or violated by the force of superior authority. However, there is a meaning of inalienable that is verifiably a distinguishing characteristic of certain rights: Some rights cannot be alienated voluntarily by means of sale. Most notable among these rights are those of citizenship - the rights to vote and to receive a passport, and a number of unspectacular entitlements, such as eligibility to apply for Fulbright Scholarships. These rights are inalienably attached to the person on the basis of some intrinsic characteristics of that person; and they can be called rights of person. 
There are other rights for which alienation is fully expected and socially facilitated. They can be called property rights. We shall say that if some characteristic of a resource is subject to legitimate and legally protected voluntary alienation, then there is a property right in that characteristic. For example, a person may have the right to reside in a hotel with an annual lease; this is a use right. But if this person has the right to sell this lease, then there is a property right in the lease (characteristic) of the hotcl (rcsource). ${ }^{1}$ Furthermore, when one alienates some characteristic of a resource, one sells the property rights that adhere to the characteristic. So, when the right to use a thing or to received revenue from it is sold, the right to sell it is also sold. For this reason, we may say that property rights generate rights in property.

For example, a hotel is a resource with a multiplicity of characteristics, each of which may bear use and property rights and each of which is subject to a decoupling from the set of other characteristics. Hence, its occupants may have alienable use rights to their apartments, and some business firm may have alienable rights to manage it, while someone else may hold alienable rights to receive revenue. Finally, the right to destroy or alter the hotel may be controlled by the state in terms of statutes concerning historical preservation. However, the contemporary implication of "owning the resource (or property)" is essentially that one holds alienable rights to the revenue generated by that resource and that the market value of this resource depends (perhaps in a complex manner) on its expected future stream of revenue. Selling the resource usually means selling the rights to this future stream, notwithstanding the existence of other parties who own other valuable characteristics of the resource and whose presence will generally affect negatively its market value. The "property" will be sold together with the various encumbrances imposed by others.

In many societies, it would appear that women have been transferred among groups in exchange for some form of wealth. There is hardly any part of the globe that has not seen this practice. However, it was seldom the case that all rights in those women were exchanged. Rather, rights in only a limited number of the characteristics in those women have been exchanged for wealth-those characteristics being related most prominently to fertility and economic productivity. Only rarely has the right of alienation been transferred to the wife-takers; hence, it could be claimed that neither she nor any of her characteristics were property.

Some theorists (e.g., Gregory, 1982; following Mauss, 1925) claim that a defining feature of gifts in lineage-based ("tribal") societies is that the gifts are not alienated. Rather, gifts are offered as a means of creating social bonds between individuals and groups and this function of gifts requires that they remain attached to the giver. Bartered goods, on the other hand, are seen to be fully alienated. However, in order for a gift to be inalienable, it must be the case that the receiver has no right to give it to another without the permission of the original giver. This form of inalienability is observed in the case of "major" marriage in Imperial China; a 
bride who came with dowry was not transferred together with a right of alienation. Those rights had not been purchased by her husband (or her in-laws). She could be sold only with the permission of her parents (usually after the death of her husband). A concubine, on the other hand, had only a "minor marriage" (without ceremony and dowry) and she was said to be "sold" to her husband; no residual authority in relation to her was retained by her parents, allowing her to be subject to resale.

Gregory (1982) cites cases of goods transfers in Papua New Guinea where rights of various sorts are retained by the giver. However, it may be argued that these cases do not characterize gifts in general. In the more general case, a person hopes that his or her gift will be preferred by its receiver to anything that the receiver can obtain in exchange for it and that, therefore, it will not be alienated. To see why, suppose that in an exchange of gifts $\mathrm{Y}$ gives $\mathrm{y}$ to $\mathrm{X}$ in exchange for $\mathrm{x}$. This exchange can lead to a lasting friendship when each side perceives that the relationship is mutually beneficial. However, if $\mathrm{X}$ decides to trade $\mathrm{y}$ for $\mathrm{z}$ (alienating the gift), there is an implication that $X$ would prefer a relationship with $Z$ to one with $Y$. Since $x$ is an exchange equivalent of $y, X$ may have been able to obtain $z$ by using $x$ at lower transaction costs and would be better off with a relationship with $\mathrm{Z}$ to the exclusion of a relationship with $\mathrm{Y}$. Or, it is possible that $\mathrm{Y}$ might be better off seeking a relationship with $Z$ (who apparently likes $y$ very much) to the exclusion of $\mathrm{X}$; or, finally it may imply that $\mathrm{X}$ is interested in $\mathrm{Y}$ only in order to effect a relationship with $\mathrm{Z}$ - where $\mathrm{y}$ is simply being "used." In any case, the social relationship between $\mathrm{X}$ and $\mathrm{Y}$ is threatened by the alienation of $\mathrm{y}$. However, these concerns are unlikely to arise if $\mathrm{X}$ has used $\mathrm{y}$ for many years and barters it as a worn-used item. Hence, we can say that y was alienable at all times, but that its immediate alienation would have had unfortunate implications for the viability of the relationship between $\mathrm{X}$ and $\mathrm{Y}$. This is unlike the Chinese case mentioned above. In that case, the laws of the Imperial State forever constrained the alienation of a dowered bride, independently of her age and condition.

Demsetz (1967) tells the story of how property rights developed among the Montagnais in the regions around Quebec during the 17th and 18th centuries. This Native American group became involved in the fur trade and sought to protect the exploitation of fur resources in its immediate domain from others. It did so by securing privileged use rights for each agnatic group to specific blocks of land. In the absence of these rights, there might have been a tendency for some people to exploit aggressively those common resources for personal gain to the disadvantage of all: a "tragedy of the commons."

This is a rather commonplace situation. However, Demsetz is wrong to say that this a story about rights in property. We are informed by Leacock (1954) that these groups could not alienate their holdings in land to other agnatic groups or to persons in other tribes: 
Nor is there any prestige attached to holding a sizable territory or any emphasis on building up and preserving the paternal inheritance. Neither can land be bought or sold. In other words, land has no value as "real estate" apart from its products. What is involved is more properly a form of usufruct than "true" ownership (pp. 1-2).

The story of the Montagnais is one about the conversion of an open-access resource (to which no one holds any rights whatsoever) into a commons (to which only members of the agnatic group have rights of use). This basic confusion has been strongly attacked by Bromley (1989), McCay and Acheson (1987), and others. There is an unfortunate tendency to attribute to the commons the potential weaknesses of open access. This error is implicit in Demsetz' discussion of the Montagnais: He fails to recognize that the benefits of restricted use can be realized with the commons, having conflated the commons with open access, anc he is forced to attribute these benefits to private property.

\section{PRIVATE PROPERTY}

The meaning of "private property" has been widely confused. "Private" is often thought to imply "personal" or individual ownership, perhaps because there must be some agency-some legal person-who has the capacity to own or to effect the alienation of resource characteristics. However, this entity can be a group of individuals of any enumeration: a business corporation or even a nation-state (consider the Louisiana Purchase).

Nevertheless, private property rights are rights of a particular form. As a technical term, private property rights are embodied in a specific rule for the allocation of rights to revenue from a production process involving human and nonhuman resources. In particular, this rule specifies that all of the revenue generated by a process of cooperative production belongs to the owner of capital (and/or natural resources). In the same way that enclosures removed the use rights of peasants, private property rules remove from workers the rights to shares of the product (as in the "putting out" system and other forms of piecework).

Lacking membership in the group that holds rights to revenue, the owners of human resources receive wages in exchange for the alienation of work effort. While it is conventional to claim that the wages constitute a share of the product, that is not the case. Even if the market value of the product suddenly falls to zero, the earned reward to labor remains unchanged. Given private property, the market value of the product becomes independent of the exchange value of productive effort. Hence, private property (as a subset of property) is characterized by the right to receive the total returns from cooperative production, together with the right of productive agents to receive market-clearing side payments.

By contrast, De Allessi (1980) says that private property means that:

the owner has the exclusive authority to choose how the resource he owns will be used, as long as the selection does not affect the physical attributes of goods owned by others. Moreover, he has the exclusive right to receive the income generated by the use of his 
resources and to exchange his property rights with those of other individuals at mutually agreeable prices (p. 4).

In this definition, De Allessi clearly indicates alienability as a characteristic of property and the exclusive right to revenue as the characteristic of private property. But he adds to this definition the unconstrained right to manage this resource. This additional right is complementary to the right to receive revenue and much beloved by the holders of property rights. However, it is not a necessary attribute of private property; more importantly, it very rarely occurs. One of the salient issues of public policy is determining the socially appropriate limitations to be applied to the right to manage privately held resources. But more critically, by omitting any reference to workers in his definition of property, De Allessi obfuscates the distributional implications inherent in the structure of private property.

We cannot really understand the meaning of private property unless it is positioned in relation to the set of alternatives. The system of private property, as a method for determining the distribution of benefits among factors of production, is unique and revolutionary relative to traditional systems. In the latter systems, rights to resources are most commonly defined by shares of the total product, as in sharecropping (sharing the output) or direct demands on shares of work effort (as in some forms of the feudal system). Or, benefits may be allocated on a communal or household principle within families, lineages, tribes, and tribal states. In these systems, work effort is rarely drawn from a market on the basis of an exchange principle; hence, work effort has no socially defined exchange value. In the absence of that exchange value, there is no way to define the social cost of production in real terms. Instead, the validity of any allocation of work or reward is determined not in terms of the logic associated with rights in property but by reference to an ideological construct that defines the responsibilities of various categories of person to the corporate group (Bcl1, 1987-1988). The devclopment of systems of private property involved the general suppression of such preexisting systems in favor of a system in which direct producers receive side payments rather than shares and work effort becomes the property basis of consumption, consumption being no longer a right of person.

Many economists blanch at the suggestion that capitalism is a system of distribution that ousts workers from ownership of their product. Apparently, only a Marxist, or someone of similarly malevolent temperament, would make reference to this fact-inducing a denunciation of capitalism for its "alienation" of workers from their product and announcing socialist revolution as the ineluctable solution. It is for this reason that discussions of rights of person tend to be suppressed. However, we should not allow these political concerns to interfere with our understanding and analysis of social systems. 


\section{RIGHTS OF PERSON}

There are many rights that cannot be alienated by the person who holds them; they can be transmitted only to heirs. Furthermore, these heirs qualify for ownership by virtue of age, sex, and parentage: that is, by birth not by achievement. In the context of contemporary capitalism, we find that a person's right to vote, or to be free from slavery, or to have freedom of speech, cannot be sold. Nor can one sell the responsibility-cum-liability to serve in the military. These are rights and liabilities that reside with the person by some principle of entitlement rather than in the resources to which a person is entitled. They arc rights of person.

However, contemporary ideology is quite uncomfortable with categories of person as factors in the structuring of a social system. The good (bourgeois) society is thought to be constructed, at least metaphorically, through a social contract among socially equivalent individuals. People may differ in their wealth accumulations, but not in their right to accumulate; they may differ in their innate capacities, but not in the right to express and develop fully those capacities. We have here the idea of society as a collection of individuals who lack intrinsic differentiation. Categories of person, on the other hand, recall the too-slowly weakening legacy of a feudal past, where a person's ultimate social placement and achievements were largely a function of sex and parentage.

It was against such feudal ideologies that the bourgeoisie required a philosophical alternative on the dawn of its ascendancy. The alternative adopted-rights in property - was revolutionary in form and consequence. However, the displacement of rights of person by rights in property has always been quite selective. Most prominently, citizenship has been preserved as the basis of person-categories, with rights being sharply curtailed for the noncitizen. Age, too, remains an unchallenged basis for formal differentiation, so that legal differentiations apply for those under the ages of 18 or 21 and to those over the ages of 55, 62, or 65 . Gender and racial classifications also have been traditional bases of person-category, but often under conditions of questionable legitimacy. The purposes for which rights of person are derived and ideologically justified vary widely. The social history of a group, its current and past forms of social organization and technology, and its class structure and power relations all conspire to give specific form to its system of rights.

Although Demsetz (1967) does not argue explicitly against all rights of person, his use of the exchange paradigm in attacking selected rights and responsibilities could be applied quite broadly. Demsetz (1967) argues for the displacement of rights of person by rights in property - for example, suggesting that military service should be induced by means of higher wages instead of the draft. And if the draft must continue, he favors allowing those who are subject to it to offer a cash payment for exemption. That is, he opposes this basic responsibility of citizenship unless it can be converted into a property that is subject to purchase by the state. 
One way of accommodating the concern of Demsetz would be to confer full rights of alienation upon draft status, allowing it to be sold to the highest bidder in an international market for military personnel. ${ }^{2}$ The person who seeks military exemption must be replaced; if a military obligation were converted into a lienencumbered property, its replacement could become the responsibility of the original owner.

The fundamental premise of the argument in favor of granting rights in a military obligation is that we can maximize the aggregate social product by permitting the execution of mutually beneficial exchanges. Since the sellers and purchasers of a right or obligation are all better off, the society must be better off-given a conception of society as a simple collection of such individuals.

Demsetz is concerned about the lack of property rights in other situations: He insists that "freedom" should be property, so that its optimal allocation among persons can be achieved:

\begin{abstract}
A law which gives the firm or the taxpayer clear title to slave labor would necessitate that the slave owners take into account the sums that slaves are willing to pay for their freedom. . . . It is the prohibition of a property right adjustment, the prohibition of the establishment of an ownership title that can thenceforth be exchanged, that precludes the internalization of external costs and benefits (p. 349).
\end{abstract}

While this argument may represent a fine example of hardheaded economic reasoning, it reflects an unawareness of rights that rest on principles other than the logic of property. The price-theoretic form of that logic assures us that no right can be optimally allocated among persons unless it is placed on the open market. For example, by converting the right to vote into property, the state would allow those rights to accumulate in the hands of those for whom they can be more instrumental and allow the previous owners of those rights to receive preferred alternativesmaking both parties better off. Even the right to free speech may find a limited market. Presumably, the purchaser, while enjoying no greater freedom, would benefit from the silencing of specific others (as in legal proceedings).

However, we understand from history that the nature of a society - the structure of social classes, the central dynamic forces shaping the growth in population, technology, and wealth-depend on how rights are allocated among groups and individuals. For example, we prefer that the economically powerful not be able to purchase votes. The general social consequences are thought to overwhelm the benefits of isolated dyadic exchanges in property rights. Similarly, the decision to abolish slavery did not rest on some arcane observation on the benefits of mutual and voluntary exchange processes. It was a choice between two fundamentally incompatible ruling elites, such that the social infrastructure and public policies of one group could not coexist with those of the other. It was a choice between rural slavery and its associated mercantile underpinnings versus an urban industrial capitalism based on free labor. These are meta-societal matters that cannot be addressed by the algebra of indifference curves. 


\section{THE RIGHT OF PRIOR POSSESSION}

There has, perhaps, never been any right more fundamental to the development of social relations and social systems than the right of prior possession. Yet, few of us are aware of it. It is not part of the set of rights enshrined in the Constitution or in the noble speech of the politicians of recent times. Yet, no right can be more fundamental. It is on the basis of this traditional right that a person can claim indefinite use to land that he clears for cultivation, so long as he or she continues to make effective use of it. It is the basis of the transmissible use rights of serfs and peasants to their share of the arable in the absence of formal, or state, codification. The right of prior possession has been essential to the social order.

The right of prior possession suggests that the initial occupant of a resource should be allowed to use it without undue compromise from the actions of others. The continued operation of the right of prior possession can be seen daily in the form of "Do not trespass" signs along roadways. Without the presence of such signs, a person could covertly make a "conventional use" of the unoccupied resource, either for a walking path or as a place of permanent residence. It then becomes feasible that these conventional uses take precedence, by right of prior possession, over alternative uses subsequently sought by the owner of property rights.

If a residential community exists prior to the planned construction of a polluting factory, the liability for that pollution (in health losses or housing values) must be incident entirely upon the factory. By the right of prior possession, the community should not be faulted for having located itself in the lovely valley that subsequently and unpredictably became the potential site of a belching factory. Yet, the analytical edifice constructed by Ronald Coase (1960) rests critically on a casual denial of the right of prior possession. He refers to this right as the doctrine of lost grant. This doctrine states "that if a legal right is proved to have existed and been exercised for a number of years the law ought to presume that it had a legal origin" ( $p$. 14). In reference to this doctrine, Coase says that "the reasoning employed by the courts in determining legal rights will often seem strange to an economist," for whom, he believes, maximal economic production is the only relevant criterion (p. 15). The inscrutability of judges on these matters arises from that fact that the doctrine of lost grant is a right that cannot readily be converted into a property right, since it adheres necessarily to the person whose situation was prior. (A person who purchases a house from an original owner, after the construction of the factory, has no claim for damages.)

Coase presents the case of a physician who builds an examination room whose walls adjoin that of the neighborhood baker, only to find that the noise of the baker's machines is disturbing to his business, and files suit against the baker. The court decided in favor of the physician! Coase supports this judgement on the grounds that the baker and the physician are equally at fault, 
arguing that the noise of the baker's machinery caused no nuisance until the building of the room by the physician. He is indifferent to the distinction between two circumstances: (1) the baker has the option of paying for the right to continue operations, or (2) the physician has the option of paying for him to stop, because they differ only in the consequences for the distribution of income, not the level of total production.

But the right of prior possession is not designed to determine the optimal distribution of income. It is related, instead, to the maintenance of orderly social processes, much the same way that the rules of rights of way are useful in various modes of transportation. A person who possesses rights of way, or who holds rights of prior possession, may be willing to compromise those rights when provided adequate compensation. A person hurrying to the hospital could (in the absence of transaction costs) purchase rights of way from their "natural owners" (say, those with green lights). But when a violation of rights of way leads to an accident, the two parties are not equally at fault, even though both cars are necessary to the accident. ${ }^{3}$ Hence, a more balanced solution to the baker-physician problem would be to allow the alienation of rights of prior possession, when appropriate. In this case, the physician could pay the baker for any compromise of his rights of prior possession. This option is technically superior to that chosen by Coase, who favors the judicial destruction of a valuable asset, the asset inherent in the right of prior possession, and the creation of stronger rights in property to the advantage of the gentry. This does not constitute a Pareto-optimal change - that is, we have no basis for claiming that society is better off. Furthermore, one cannot argue effectively for measures that increase output (the efficiency criterion) if those measures involve the massive destruction of valuable assets.

The abrogation of the baker's rights of prior possession in favor of the property interests of the politically dominant gentry, in the case discussed by Coase, was part of a more general process by which the traditional rights of the peasantry gave way to the demands of mercantile and industrial interests. Coase is certainly free to support the special interests of the gentry; however, he is not plausibly indifferent to the distribution of income when he denies the baker's right of prior possession in favor of rights in property.

\section{PROPERTY RIGHTS, EFFICIENCY, AND DISTRIBUTION}

One of the most exciting aspects of anthropological information is the great variety of forms that resources and rights may take and have taken among the cultures of the world. Social systems are structured by the set of rights of person and rights in property that are enforced and by the attributes of available resources. These systems of rights orient direct demands for shares in social resources and have implications for the probable distribution of those resources.

For example, the system of private property grants revenue rights to individuals and implicitly removes revenue rights from other persons. However, in the man- 
agement of the social system, wage earners may be given rights to "organize" into bargaining units and those units may be allowed certain prerogatives in asserting their claims. The activities of these bargaining units may negatively affect the opportunities of wage earners who lack bargaining power, as well as affecting the net revenue of employers. Hence, the "right to organize" generates a particular division of the social product among owners of private property, unionized wage workers, and nonunionized wage workers. On the other hand, there are capitalist states, such as Taiwan and South Korea, whose political structures facilitate the denial of workers' demands for organized representation, minimum wages and other benefits, with the consequence that a larger share of the social product may accrue to the owners of capital.

Some social systems enjoy the reinforcement offered by ideologies that assert the natural character of their system of rights and responsibilities. A natural character is claimed in order to deflect discontent from those who would be outraged by obvious fact of human intervention. In traditional systems, it is the natural differences among people, by sex, age, and parentage that are most common as bases of natural differences in rights to resources. Although this form of rationalization has long been under attack by the ideologists of capitalism, capitalism has its own form of the natural; it is expressed by the ideology of economic efficiency.

Economic efficiency is achieved when it is not possible to produce a particular combination of goods at a lower cost of inputs. Since "inputs" include the providers of labor, the fact that their rewards are minimized has no obvious objective merit. However, it is easily shown that a reduction in the unit cost of inputs will commonly lead to a higher level of production, provided that the level of demand of the product is not adversely affected by the reduced cost of inputs. Hence, if we use as an "objective" criterion of social benefit, the value of total output, it would appear that a society organized for efficient production is preferred, provided that we are indifferent to the distribution of income. This is precisely the Coasian principle of optimality.

However, the doctrine of economic efficiency cannot possibly be indifferent to the distribution of income, since efficiency is an ideology for the rationalization of a particular form of distribution. This fact is more readily seen when we place private property against its historical predecessor, the feudal regime of common nonproperty resources. A number of societies have made the transition from systems of nonproperty resource management to systems of private property. In every case that I have examined, this transition has been predicated on an increase in the size of the rural population that placed unacceptable pressure on the system of corporate shares. That is, as the population of serfs grows, they become redundant at the margin. At the same time, their increasing population induces pressure for a larger share of the common resources, at the expense of the elite. In this way, population pressure becomes inconsistent with the maintenance 
of traditional corporate shares and prompts a search within the elite for an alternative social formation. In England, this situation was reached by the 17th century; it was reached in Russia by the beginning of the 19th, in the Philippines by the early part of the 20th century, and so forth. In each case, the broader social, technological, and political contexts were particular to time and place, but in each case it is clear that the norms of corporate shares became unsustainable on account of demographic forces.

In contrast to traditional criteria of allocation, the doctrine of efficiency thrives on a redundancy of hands, and the immediate consequence of abandoning traditional forms has been to reduce the share of the social product allocated to the direct producer. There is found in the system of private property a means of increasing economic efficiency-increasing the share of the social product to the upper classes-by means of a rule that grants all rights to revenue to the owners of land and abolishing the traditional use rights (rights to revenue) of the common people. Private property in land in the face of an excessive rural population provides the conditions for the subjugation of the peasantry and working classes to the standards of economic efficiency.

Bromley (1989) expresses concern over the way in which the set of rights embodied in the status quo influences judgements regarding the economic efficiency of a planned institutional transaction. His example is of safety for mineworkers who, in the absence of any socially defined rights to safety on the job, may demand additional compensation for working in unsafe conditions as a condition of employment. Alternatively, the workers could be offered an annuity that covers the full cost of accidents and internalizes the cost of unsafe conditions to the firm. The equilibrium amount of safety under these two regimes is likely to differ. How much you will pay for safety is different from how much you demand in compensation for giving it up. So, argues Bromley, there is a significant wealth (or income) effect that differentiates the desirability of these two regimes from the perspective of the worker. Ilence, characteristics of the status quo make a difference in the final outcomes, in contrast to the implications of the standard Coasian analysis.

Bromley's discussion explicitly presupposes that workers have the option of actually taking a safe versus an unsafe job, so that they can demonstrate an aversion to a lack of safety by rejecting unsafe jobs that lack adequate wage differentials. However, if there is a "redundancy of hands" in the relevant labor market, due to chance or to governmental policies that facilitate labor mobility to the job site, the optimal price of safety will be zero in either case. Some workers will avoid mining on this account, but many others will find no alternative. Indeed, if the latter suffer an occupational disability due to ethnicity or geographic location, the wages paid in unsafe mining jobs may be below those of (otherwise comparable) safe jobs. 
For Bromley: "The issue is one of how to define efficiency, and which pointthe status quo or some alternative institutional arrangement-will provide the basis for the efficiency calculation. Who will speak for the miners?" (p. 115). However, there is no contest here. If the annuity increases production costs to any extent, it will almost certainly be output-reducing in equilibrium and, hence, be inferior to the status quo ante by efficiency criteria, even if it constitutes only a minor nuisance to the employer and a great benefit to the workers. Efficiency does not depend on the relative gains of mineowners and miners. It is, at least formally, the gain of an abstract consumer that matters-a consumer who is neither a miner nor a mineowner.

Bromley's annuity for safety implies that rights to safety are alienable-they have property rights. Were he to consider the right to safety as a right of person, a conflict with the efficiency criterion would be immediate. As we have seen in our discussion of Demsetz, the logic of indifference curves contests such claims. But we know that if the right to safety were established by the Congress of the United States, it would be inalienable. Congress would certainly combine a mandated annuity scheme with regulations of safety standards. Congress will choose this solution because the set of workers is not unitary in character. Any subset of workers that lacks a concern for safety, or that is desperately in search of employment, can frustrate the "entitlement" of others.

The same argument can be made about the entitlement to be free from enslavement: Unless those who are least advantaged by this right hold it as a right of person, society as an institution will suffer the consequences. The law against slavery (or lack of safety) is likely to disadvantage the hapless and desperate individual who has only his freedom (or life) to offer. It is for the sake of others that he is restrained.

\section{CONCLUSION}

The arguments of economic theory suggest that the consumer is sovereign in a perfectly competitive, efficient, productive system. It is in relation to this theory that rights in property have their fullest rationalization. Rights of person, on the other hand, depend on political determinations of appropriateness in relation to defined person-categories. The contemporary rationalization of these determinations is associated with theories about the sovereignty of independent citizens within a republican form of representative government. These theories share with the neoclassical model a conception of people as independent, perhaps atomized, and self-interested-people whose elected representatives are expected to realize the social optimum through public choice.

Even if these two forms of sovereignty operated perfectly in accordance with the norms relevant to each, the development of a properly articulated combination of rights of person and rights in property would be difficult to achieve. However, neither is perfect. The market system has often showed the roughness of its edges, 
leading to the more active intervention of the public sector in the reallocation of resources; under the rubric of public choice, many economists have launched a wide-ranging attack on government as decision maker, demonstrating the inefficiency of government and the potential increases in efficiency achievable from unfettered market operation. It is a pity that so many good minds have been committed to this task. It would be senseless to judge a new consumer product on the basis of a congressional vote, and it is equally senscless to cvaluate rights of person on the basis of efficiency criteria. Bromley's attempt to mold an efficiency argument in support of occupational safety could only lead to error.

As I have shown, the logic of efficiency is properly to be imposed upon only a very narrow domain. Outside of that domain, it becomes an elephant among the petunias, crushing all within its path. Not even a (nonalienable) right to vote is defendable on efficiency grounds, nor is the obligation to forswear one's own personal enslavement.

Amitai Etzioni (1988) has suggested the desirability of expanding the neoclassical code to include moral dimensions. The moral imperatives that he posits are precisely those that support and rationalize rights of person. However, rights of person cannot be advanced by adding new arguments to utility functions. The necessary "new economics" cannot be a thematic variation on the old. The task of socioeconomics is to determine the attributes that characterize the socially optimal configuration of rights of person and rights in property, given that the ideologies that support the former are disjoint from the ideologies that support the latter.

Acknowledgment: This work was supported by an Irvine Faculty Research Grant, 1993-1994, and it was significantly modified after being read before the Annual Meeting of the Society of Economic Anthropology, March 1994.

\section{NOTES}

1. Of course, a right must be held with some degree of security in order for an expenditure to be justified in exchange for it. Rights that are at risk of abrogation suffer steep discounts in the open market. But to the degree that rights are secure, they may be sought by those lacking in them.

2. We cannot restrict the market for draft status to any subset of those who are physically capable (such as "citizens" or males only) without creating yet another right of person.

3. Rights of way are clearly rights of person because the law refuses to recognize the validity of their alienation. The police will be unimpressed by the clain that you have paid other drivers for the right to drive through the red light, since that right is not transferrable. Nor can one offer to pay the police directly for this privilege, since doing so would be an attempt to bribe a public official. Rights of way are not allowed to become property.

\section{REFERENCES}

Bell, D. (1987-198). Production and distribution within hierarchically structured cooperative groups. Journal of the Steward Anthropological Society, 16(1-2), 96-124.

Bell, D. (1991). Modes of exchange: Gift and commodity. Journal of Socio-Economics, 20(2), 155167. 
Bromley, D.W. (1989a). Property relations and economic development: The other land reform. World Development, 17(6), 867-877.

Bromley, D.W. (1989b). Economic Interests and Institutions, the conceptual foundations of public policy. New York: Basil Blackwell.

Ciriacy-Wantrup, S.V., \& R.C. Bishop. (1975). "Common property" as a concept in natural resources policy. Natural Resources Journal. 15(4), 713-727.

Coase, R.H. (1960). The problem of social cost. The Journal of Law \& Economics, 3(1), 1-69.

De Allessi, L. (1980). The economics of property rights: A review of the evidence. Research in Law and Economics, 2, 1-47

Demsetz, H. (1967). Toward a theory of property rights. American Economic Review, 57(2), 347359.

Etzioni, A. (1988). The Moral Dimension: Toward a new economics. New York: The Free Press.

Gregory, C.A. (1982). Gifts and commodities. London/New York: Academic Press.

Hudson, M. (1994). Land monopolization, tax crises and economic dissolution, from Bronze Age Babylonia through Greece, Rome and Byzantium. Paper presented to the Annual Meeting of the Society for Economic Anthropology, March.

Ingold, T. (1980). Hunters, Pastoralists and Ranchers. Cambridge, UK: Cambridge University Press.

Jeudwine, J.W. (1975 [1918]). The foundations of society and the land. New York: Arno Press.

Leacock, E. (1954). The Montagnais "hunting territory" and the fur trade. American Anthropologist, 56(5), pt. 2, Memoir no. 78.

Libecap, G.D. (1989). Contracting for property rights. Cambridge, UK: Cambridge University Press.

Macpherson, C.B. (1985). The rise and fall of economic justice and other papers. Oxford, UK: Oxford University Press.

Mauss, M. (1925 [1974]). The gift. London: Routledge and Kegan Paul.

Nugent, D. (1993). Property relations, production relations, and inequality: Anthropology, political economy and the Blackfeet. American Ethnologist, 20(2), 336-362.

McCay, B.J. (1987). The culture of the commoners. In B.J. McCay \& J.M. Acheson (Eds.), The question of the commons: The culture and ecology of communal resources (pp. 195-216). Tuscon, AZ: University of Arizona Press.

McCay, B.J., \& Acheson, J.M. (1987). Human ecology of the commons. In B.J. McCay \& J.M. Acheson (Eds.), The question of the commons: The culture and ecology of communal resources (pp. 1-34). Tuscon, AZ: University of Arizona Press.

Peters, P.E. (1994). Common property, property and social analysis. Paper presented to the Meeting of the Society for Economic Anthropology, March.

Sax, J.L. (1983). Some thoughts on the decline of private property, Washington Law Review Iurisprudential Iesture Series, 58,481

Strathern, M. (1988). The gender of the gift. Berkeley, CA: University of California Press 